February 2005 - NREL/CP-520-37418

\title{
Analysis of Depletion-Region Collection in GalnNAs Solar Cells
}

D.J. Friedman, A.J. Ptak, Sarah R. Kurtz, and J.F. Geisz

Prepared for the $31^{\text {st }}$ IEEE Photovoltaics Specialists Conference and Exhibition

Lake Buena Vista, Florida

January 3-7, 2005
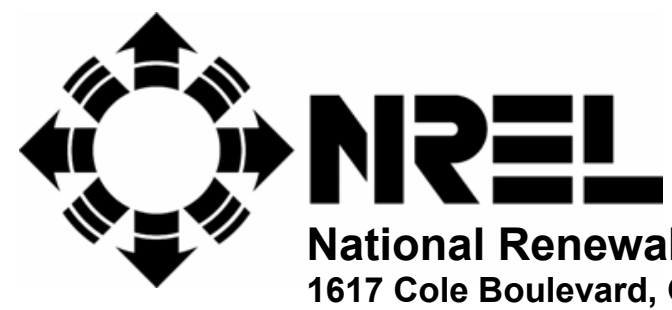

National Renewable Energy Laboratory 1617 Cole Boulevard, Golden, Colorado 80401-3393 303-275-3000 • www.nrel.gov

Operated for the U.S. Department of Energy

Office of Energy Efficiency and Renewable Energy

by Midwest Research Institute $\bullet$ Battelle

Contract No. DE-AC36-99-G010337 


\section{NOTICE}

The submitted manuscript has been offered by an employee of the Midwest Research Institute (MRI), a contractor of the US Government under Contract No. DE-AC36-99G010337. Accordingly, the US Government and MRI retain a nonexclusive royalty-free license to publish or reproduce the published form of this contribution, or allow others to do so, for US Government purposes.

This report was prepared as an account of work sponsored by an agency of the United States government. Neither the United States government nor any agency thereof, nor any of their employees, makes any warranty, express or implied, or assumes any legal liability or responsibility for the accuracy, completeness, or usefulness of any information, apparatus, product, or process disclosed, or represents that its use would not infringe privately owned rights. Reference herein to any specific commercial product, process, or service by trade name, trademark, manufacturer, or otherwise does not necessarily constitute or imply its endorsement, recommendation, or favoring by the United States government or any agency thereof. The views and opinions of authors expressed herein do not necessarily state or reflect those of the United States government or any agency thereof.

Available electronically at http://www.osti.gov/bridge

Available for a processing fee to U.S. Department of Energy and its contractors, in paper, from:

U.S. Department of Energy

Office of Scientific and Technical Information

P.O. Box 62

Oak Ridge, TN 37831-0062

phone: 865.576 .8401

fax: 865.576.5728

email: mailto:reports@adonis.osti.gov

Available for sale to the public, in paper, from:

U.S. Department of Commerce

National Technical Information Service

5285 Port Royal Road

Springfield, VA 22161

phone: 800.553 .6847

fax: 703.605.6900

email: orders@ntis.fedworld.gov

online ordering: http://www.ntis.gov/ordering.htm 


\title{
Analysis Of Depletion-Region Collection In GalnNAs Solar Cells
}

\author{
D.J. Friedman, A.J. Ptak, Sarah R. Kurtz, and J.F. Geisz \\ National Renewable Energy Laboratory, Golden, CO 80401 USA
}

\begin{abstract}
We provide qualitative insight into depletion-region collection in GalnNAs cells to (1) understand the effect of diffusion length $\mathrm{L}$ on the $\mathrm{QE}$; and (2) describe the magnitude of $L$ required to get adequate current from the cell. We use Wolf's equations for the QE including a drift field $E$, and model $E$ as being equal to the junction built-in voltage distributed uniformly across the depletion region. This allows us to calculate the QE as a function of $L$ and depletion width $W_{D}$. We show that if $L$ is sufficiently small, increasing $W_{D}$ can actually decrease the $Q E$. To determine how long $L$ needs to be in a practical GalnNAs junction, we calculate from the QE the short-circuit current density as a function of $W_{D}$ and $L$. This allows us to estimate that $L_{a m b i p o l a r}$ needs to be greater than roughly $1 \mu \mathrm{m}$ in order to obtain enough photocurrent for the 4-junction application, giving guidance to the experimental effort to develop such cells.
\end{abstract}

\section{INTRODUCTION}

Considerable effort has been spent on developing 1eV GalnNAs junctions for future-generations of highefficiency multijunction devices [1-5]. However, the poor diffusion lengths in this material result in unacceptably low quantum efficiencies (QE): as-grown pn junctions typically show QE $<20 \%$.

With the introduction of a wide depletion region, i.e. a pin structure, to collect photocarriers, greatly improved

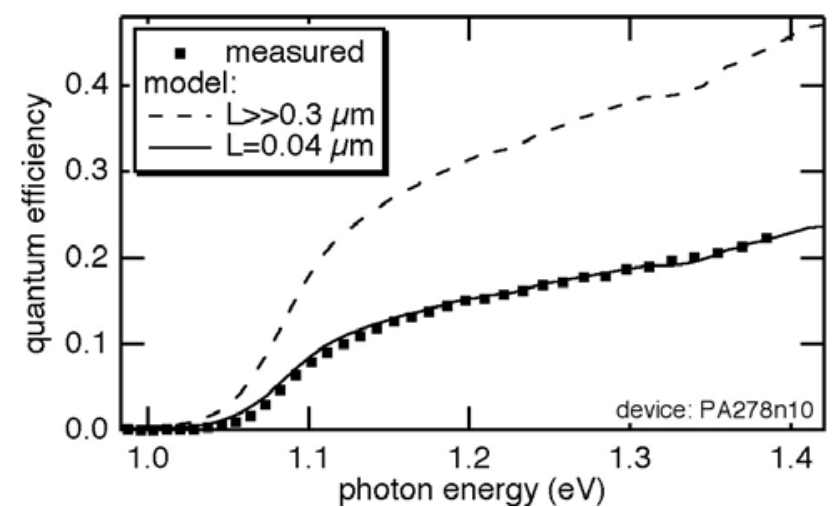

Fig. 1. Dots: measured $Q E$ of a GalnNAs junction with $\mathrm{W}_{\mathrm{D}}=0.3 \mu \mathrm{m}$. Dashed line: modeled $\mathrm{QE}$ assuming complete collection in the $0.3 \mu \mathrm{m}$ depletion region. Solid line: Modeled QE assuming incomplete collection (see text).
QEs > 70\% have been achieved [2]. Considerable progress has been made in five- and six-junction structures for which this magnitude of $Q E$ is sufficient, due to the reduced current-density requirements on the GalnNAs junction for current-matching in these structures [4,5]. However, for application in the simpler GalnP/GaAs/GalnNAs or GalnP/GaAs/GalnNAs/Ge structures, $Q E>90 \%$ is required. Such $Q E s$ have not been achieved for 1-eV GalnNAs grown by MOVPE, although significant progress has recently made using MBE growth [6]. One problem has been the difficulty of obtaining sufficiently large depletion widths $W_{D}$. However, merely obtaining large $W_{D}$ is not sufficient.

The drift field in the depletion region helps move the photocarriers to the junction, resulting in an effective collection length $L_{C}$ for photocarriers which is enhanced compared to the (zero-field) diffusion length $\mathrm{L}$. It is conventionally assumed that every photocarrier in the junction depletion region is swept to the junction by the drift field and collected; i.e. that $L_{C}>W_{D}$. For this to be the case, it is necessary for the photocarriers to live long enough for the field to sweep them to the junction. However, if the diffusion length $L$ is very low, even the enhancement in $L_{C}$ provided by the drift field may not be enough to get the required $L_{C}>W_{D}$.

The consequence would be a QE lower than if there were complete collection of carriers from the depletion region. Figure 1 gives an experimentally observed example. It shows the measured QE for a GalnNAs junction whose $W_{D}=0.3 \mu \mathrm{m}$ as determined by capacitance-voltage profiling. For comparison, the dashed line is what the QE would be for complete collection in the depletion region, showing that in this cell a significant fraction of the photocarriers generated in the depletion region are not being collected. In contrast, if we get rid of the oversimplified assumption of complete collection in the depletion region, we can account for the measured $Q E$ as shown by the solid line, to be discussed in more detail below.

Here we focus exclusively on collection in the depletion region. The collection of photocarriers in the "flat-band" regions of GalnNAs solar cells is discussed by Kurtz [7].

\section{OBJECTIVE}

Because the minority-carrier diffusion lengths in GalnNAs are low, in order to understand collection in the 
depletion region well enough to take advantage of the driftfield enhancement, it is necessary to account for the dependence of the collection length $L_{C}$ on the diffusion length and on the drift field. Our objective here is to provide this understanding by modeling the effect of the enhanced collection in GalnNAs junctions, so that we can (1) explain the observed phenomenon (illustrated qualitatively in Fig. 1) that increasing $W_{D}$ sometimes results in decreasing, rather than increasing, QE; and (2) understand and describe what magnitude is required for $L$ in order to get the required current from the cell. Our approach is not intended to be a fully quantitative description of the junction, the detailed complexities of which (e.g. ambipolar transport, trapping by localized states, etc) would be difficult to treat analytically.

\section{APPROACH}

In order to gain insight into the characteristics of drift collection in these devices, we use an idealized model of the junction shown in Fig. 2 to capture the essential features. The junction is assumed to be fully depleted, with a uniform field $E=V_{b i} / W_{D}$.

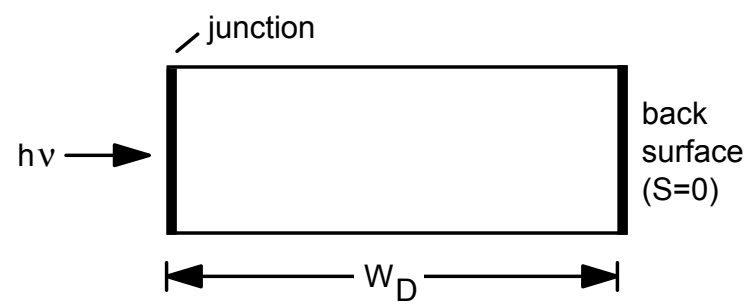

Fig. 2. Schematic of the model for the junction.

Wolf [8] provides the quantum efficiency of the illuminated junction including the field, as:

$$
Q E=\frac{\alpha}{G} \cdot \frac{1}{b^{2}-1} \cdot\left\lfloor b-1+\frac{(1-a) e^{-G d}+(a-b) e^{-b G d}}{\cosh G d+a \sinh G d}\right\rfloor
$$

where

$$
\begin{gathered}
F \equiv e E / 2 k T, \\
b \equiv(\alpha-F) / G, \\
G \equiv \sqrt{F^{2}+1 / L^{2}}, \\
a \equiv \frac{F}{G}+\frac{S}{G D},
\end{gathered}
$$

$\alpha=\alpha(\lambda)$ is the absorption coefficient, $d=W_{D}$ is the base thickness, $S$ is the back surface recombination velocity, $D=k_{B} T \mu / e$ is the diffusion coefficient at temperature $T$, and $L=\left(k_{B} T \mu \tau / e\right)^{1 / 2}$ is the diffusion length. The carrier mobility $\mu$ and lifetime $\tau$ are assumed to be independent of field. We take $V_{b i}=0.75 \mathrm{~V}$ for a 1-eV-bandgap junction, and for simplicity assume $S=0$. These equations then allow us to calculate the $Q E$ as a function of $W_{D}$ and $L$.

\section{RESULTS}

Using our model, we can now derive insight into the effects of diffusion length and field (or cell thickness) in determining the QE. Figure 3 compares the QE calculated for three different combinations of $L$ and $W_{D}$. For $L=1 \mu \mathrm{m}$ and $W_{D}=1 \mu \mathrm{m}$, most of the carriers are collected.
Increasing $W_{D}$ to $3 \mu \mathrm{m}$ increases the QE because the cell is thicker. However, the situation changes qualitatively when we now consider a much lower diffusion length. At $L=0.1 \mu \mathrm{m}$ and $W_{D}=1 \mu \mathrm{m}$, the carrier collection is much less than at $L=1 \mu \mathrm{m}$; i.e., the field is no longer adequate to sweep all the carriers to the junction before they recombine. If we now increase $W_{D}$ to $3 \mu \mathrm{m}$, the $Q E$ actually decreases, rather than increasing as was the case for the larger $L=1 \mu \mathrm{m}$. This is because for small $L$, the detrimental effect of lowering the field (by a factor of 3 in this example) outweighs the effect of the increased thickness of the region where light is being absorbed. Thus, the QE can either increase or decrease with increasing $W_{D}$, depending on the magnitude of $L$. This is the central theme of this paper, taking us beyond the simple approximation in which increased $W_{D}$ necessarily results in enhanced $Q E$.

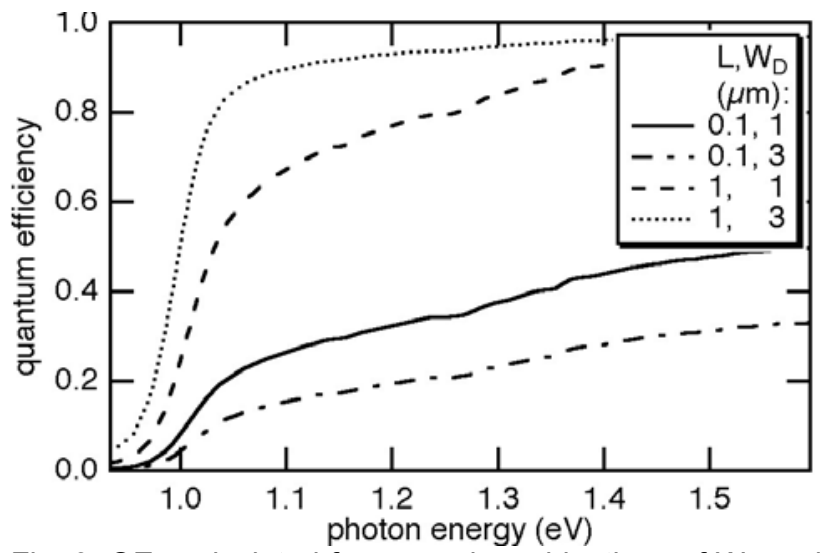

Fig. 3. QEs calculated for several combinations of $W_{D}$ and $\mathrm{L}$, for the fully depleted structure of Fig. 2 .

We can now go back to the data of Fig. 1 and, given the measured $W_{D}$ of $0.3 \mu \mathrm{m}$ in that device, see what value of $L$ gives a $Q E$ consistent with the measured data. The figure shows that $L=0.04 \mu \mathrm{m}$ is consistent with the measured QE.

Clearly, for practical devices, we cannot permit $L$ to be arbitrarily small. To quantify this, we calculate from the QE

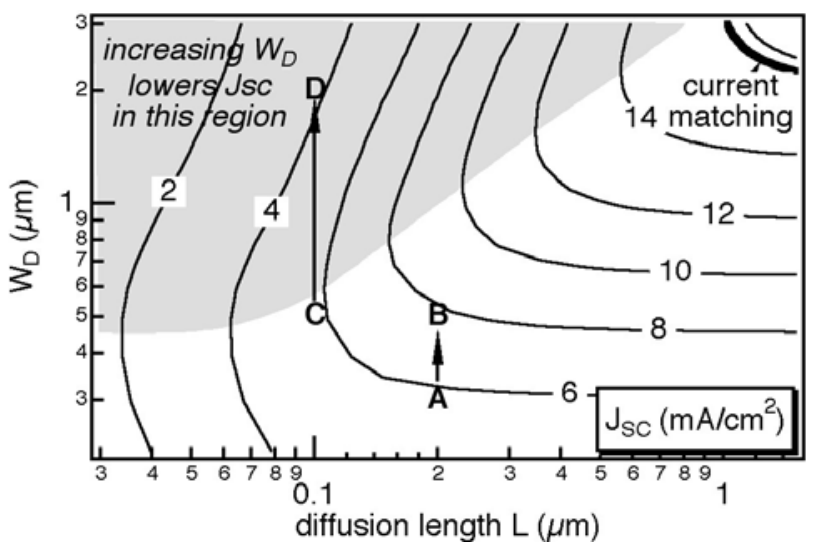

Fig. 4. Contours of $J_{S C}$ as a function of $W_{D}$ and $L$ for the low-AOD spectrum, for the model junction of Fig. 2. In the grey region, increasing $W_{D}$ decreases $J_{S C}$. Note that $L$ is the diffusion length, not the collection length $L_{C}$. 
the short-circuit current density $J_{S C}$ as a function of $W_{D}$ and $L$ necessary to obtain the current needed in the multijunction application. Figure 4 shows $J_{S C}\left(L, W_{D}\right)$ for the low-AOD spectrum. To illustrate the effect of $L$ on whether increasing $W_{D}$ is useful, consider two cases. (1) As shown by the arrow from $A$ to $B$ in Fig. 4 , we set $L=0.2 \mu \mathrm{m}$, and increase $W_{D}$ from $0.3 \mu \mathrm{m}$ to $0.5 \mu \mathrm{m}$. In this case, increasing $W_{D}$ increases $J_{S C}$. (2) As shown by the arrow from $C$ to $D$ in Fig. 4, we set $L=0.1 \mu \mathrm{m}$, and increase $W_{D}$ from $0.5 \mu \mathrm{m}$ to $2 \mu \mathrm{m}$. In this case, increasing $W_{D}$ decreases $\mathrm{J}_{\mathrm{SC}}$.

The second case is an example of a general feature of $J_{S C}$ : there is a region of $W_{D}$ and $L$, shaded in grey in the figure, in which increasing $W_{D}$ decreases $J_{S C}$. To understand why this region exists, we need to understand in more detail the effect of the drift field. The drift field results in a collection length $L_{C}=1 /(G-F)$, which is always greater than or equal to $L$; i.e. the field enhances the collection length. For zero field, $L_{C}$ becomes $L_{C}=L$, while in the limit of high field $L_{C}$ approaches $L_{C}=\mu \tau E$. As long as $L_{C}$ $>W_{D}$, all the photocurrent generated in the depletion region is collected. However, if $L_{C}$ is reduced so that $L_{C}<$ $\mathrm{W}_{\mathrm{D}}$, collection in the depletion region is no longer complete. A key point in our analysis is that the drift field decreases with increasing $W_{D}$ because the same voltage is distributed over a longer distance; and hence $L_{C}$ decreases as well. As long as $L_{C}>W_{D}$, this will not have a significant effect on the photocurrent collection, which is determined by the smaller of $L_{C}$ and $W_{D}$. But, under conditions where increasing $W_{D}$ reduces $L_{C}$ to less than $W_{D}$, the current collection will decrease rather than increase. The crossover from $\mathrm{W}_{\mathrm{D}}$-limited to $\mathrm{L}_{\mathrm{C}}$-limited $\mathrm{J}_{\mathrm{SC}}$ is given by the boundary of the grey region in Fig. 4 .

For current-matching the 1.0-eV GalnNAs junction under GalnP/GaAs junctions, for the low-AOD spectrum a $\mathrm{J}_{\mathrm{SC}}$ of $15.8 \mathrm{~mA} / \mathrm{cm}^{2}$ is needed for ideal top and middle cells. The $\mathrm{J}_{\mathrm{SC}}=15.8 \mathrm{~mA} / \mathrm{cm}^{2}$ contour is indicated in bold in Fig. 4 , and defines the minimum values of $W_{D}$ and $L$ required to achieve this current for a fully depleted cell. The contour shows that not only do we need $W_{D}>2 \mu \mathrm{m}$; we also need $L>1 \mu \mathrm{m}$. In contrast, current matching for the six-junction structure $[4,5]$ is about $8 \mathrm{~mA} / \mathrm{cm}^{2}$. The corresponding contour in Fig. 4 shows that for this current, the requirements on $W_{D}$ and $L$ are greatly reduced to roughly $W_{D}>0.5 \mu \mathrm{m}$ and $L>0.2 \mu \mathrm{m}$.

For application in a GalnP/GaAs/GalnNAs threejunction structure, it may be worth considering GalnNAs band gaps below $1 \mathrm{eV}$ as a strategy to increasing the GalnNAs current. Figure 5 compares the $E_{g}=1 \mathrm{eV}$ contours of $\mathrm{J}_{\mathrm{SC}}$ from Fig. 4 with $\mathrm{J}_{\mathrm{SC}}$ contours calculated for $E_{g}=0.95 \mathrm{eV}$. Reducing $E_{g}$ from 1 to $0.95 \mathrm{eV}$ reduces the values needed for both $W_{D}$ and $L$, making this appear to be a promising approach. Unfortunately, other studies [9] indicate that the minority-carrier properties of GalnNAs degrade so rapidly with decreasing $E_{g}$ that achieving $L=0.5$ $\mu \mathrm{m}$ at $E_{g}=0.95 \mathrm{eV}$ is probably even more difficult than achieving $L=1 \mu \mathrm{m}$ at $E_{g}=1 \mathrm{eV}$.

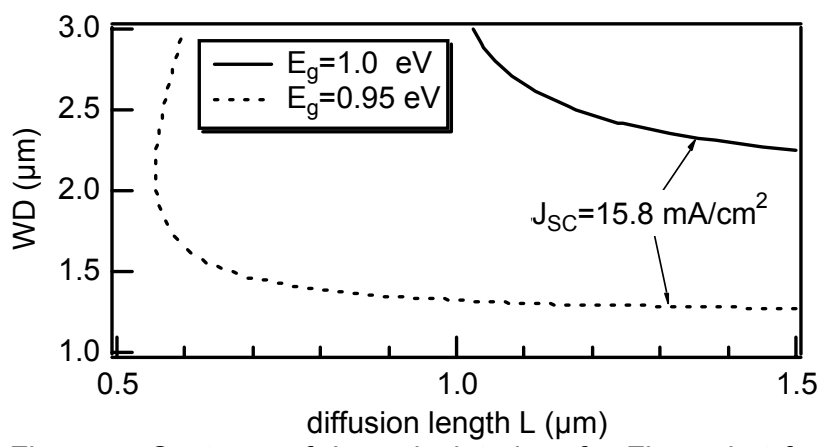

Figure 5. Contours of $J_{S C}$ calculated as for Fig. 4, but for $E_{\mathrm{q}}=0.95 \mathrm{eV}$ as well as $\mathrm{E}_{\mathrm{q}}=1.0 \mathrm{eV}$.

Furthermore, obtaining large $W_{D}$ in practice also appears to be increasingly difficult with decreasing band gap. Figure 6 plots the required depletion width $W_{D}$ (assuming $L_{C}>W_{D}$ ) as a function of junction band gap $E_{g}$ for current-matching under GalnP/GaAs junctions. The figure also shows the depletion widths we have obtained to date on MOVPE-grown GalnNAs junctions, measured by capacitance-voltage profiling. At $E_{g}=1 \mathrm{eV}$, the achieved depletion widths are within a factor of three of the needed depletion width. However, the achieved depletion widths fall off rapidly with decreasing band gap, presumably due to an increase in the concentration of either doping impurities or defects with increasing nitrogen concentration (i.e. decreasing band gap). The achieved depletion widths shown in Fig. 2 decrease more rapidly with $E_{g}$ than the needed depletion width decreases, weakening the motivation for going to bandgaps below $1 \mathrm{eV}$.

However, it may still be possible to achieve the needed depletion widths by growing the junctions with solid-source molecular-beam epitaxy (MBE) [6]. Using our model, we can estimate the diffusion length in the MBEgrown long-depletion-width junctions of Ptak [6]. Figure 7 compares the QE measured for one of these MBE devices (the $W=2.7 \mu \mathrm{m}$ device of Ref. [6]'s Fig. 2) with a family of QE curves generated by our model as a function of diffusion length. For the absorption coefficient for this $E_{g}=1.28$ eV device, we use the GaAs absorption coefficent

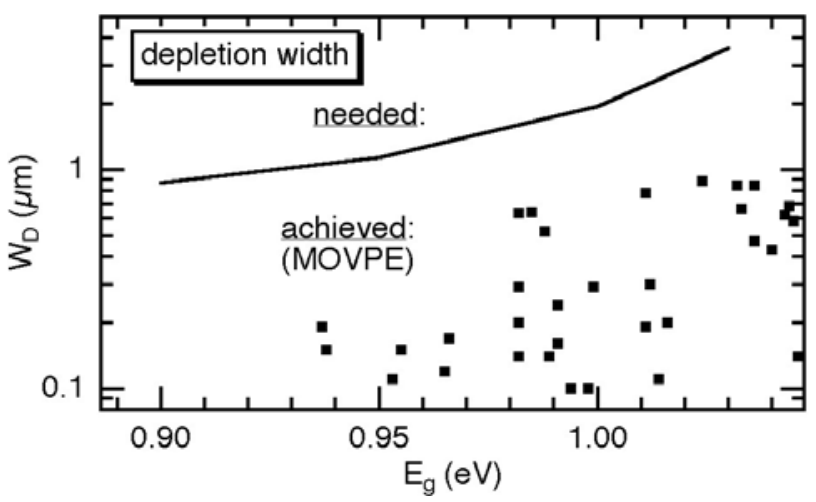

Figure 6. Depletion width needed to match the GalnNAs third junction's current to the GalnP and GaAs top two junctions in a GalnP/GaAs/GalnNAs three-junction cell. Also shown (dots) are the depletion widths that have actually been achieved for MOVPE-grown GalnNAs junctions to date. 


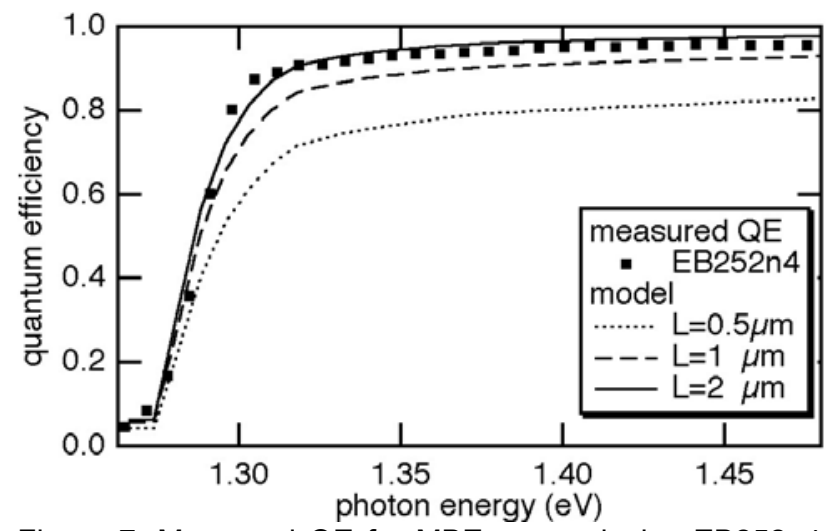

Figure 7. Measured QE for MBE-grown device EB252n4, compared to calculated QE curves from our model with various diffusion lengths.

translated down in energy to match the 1.28-eV band edge, as discussed by Kurtz [7]. The results of Fig. 7 suggest that the diffusion length in the base of this device is at least $1-2 \mu \mathrm{m}$. The next development step would be to achieve similar $L$ and $W_{D}$ in a $E_{g}=1.0-e V$ device.

\section{SUMMARY}

We have modeled drift collection in idealized fully depleted 1-eV GalnNAs solar cells to provide insight into the dependence of the $Q E$ on the diffusion length $L$ and depletion width $W_{D}$. We find that, roughly, $L>1 \mu \mathrm{m}$ as well as $W_{D}>2 \mu \mathrm{m}$ are required for current-matching in the 3or 4-junction application. The $E_{g}=1.28-e V$ MBE-grown device of Fig. 7 [6] appears to satisfy these criteria, although not yet with a $1.0-\mathrm{eV}$ band gap. Lowering the band gap from 1.0 to $0.95 \mathrm{eV}$ lowers the requirements on $W_{D}$ and $L$, although in practice it may be harder to obtain the required $W_{D}$ and $L$ at $E_{g}=0.95 \mathrm{eV}$ than at $1 \mathrm{eV}$. Alternatively, for the six-junction structure [4,5], a much less demanding $L>0.2 \mu \mathrm{m}$ and $W_{D}>0.5 \mu \mathrm{m}$ are required, an encouraging result for this device structure as these paramaters should be obtainable with MOVPE-grown material.

\section{REFERENCES}

[1] S.R. Kurtz, D. Myers, and J.M. Olson, "Projected Performance of Three- and Four-Junction Devices using GaAs and GalnP", 26th IEEE Photovoltaic Specialists Conference, 1997, pp. 875-878.

[2] D.J. Friedman, J.F. Geisz, S.R. Kurtz, and J.M. Olson, "1-eV solar cells with GalnNAs active layer", J. Cryst. Growth 195, 1998, pp. 409-415.

[3] J.F. Geisz and D.J. Friedman, "III-N-V semiconductors for solar photovoltaic applications", Semicon. Sci. Technol. 17, 2002, pp. 769-777.

[4] R.R. King et al., "Metamorphic III-V materials, sublattice disorder, and multijunction solar cell approaches with over 37\% efficiency", 19th European Photovoltaic Solar Energy Conference and Exhibition, 2004,

[5] M. Meusel et al., "European roadmap for the development of III-V multi-junction space solar cells", 19th European Photovoltaic Solar Energy Conference, 2004,

[6] A.J. Ptak, D.J. Friedman, C. Kramer, and M. Young, "Enhanced-depletion-width GalnNAs solar cells grown by molecular-beam epitaxy", 31st IEEE Photovoltaic Specialists Conference, 2005,

[7] S. Kurtz et al., "Effect of nitrogen concentration on the performance of Gaxln1-xNyAs1-y solar cells", Proceedings of the IEEE Photovoltaic Specialists Conference, 2005,

[8] M. Wolf, "Drift fields in photovoltaic solar energy converter cells", Proc. IEEE 51, 1963, pp. 674-693.

[9] D.J. Friedman, J.F. Geisz, W.K. Metzger, and S.W. Johnston, "Trap-dominated minority-carrier recombination in GalnNAs pn junctions", Appl. Phys. Lett. 83, 2003, pp. 698-700. 


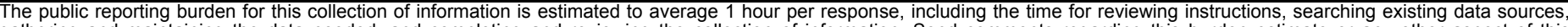

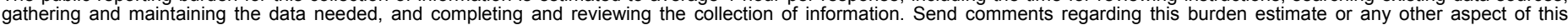

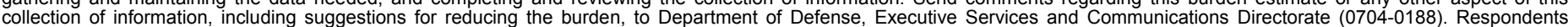

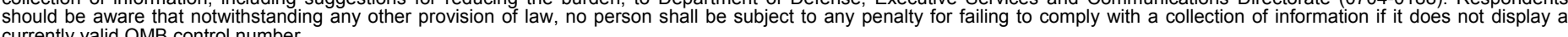

PLEASE DO NOT RETURN YOUR FORM TO THE ABOVE ORGANIZATION.

\section{REPORT DATE (DD-MM-YYYY) \\ February 2005 \\ 2. REPORT TYPE \\ Conference Paper}

4. TITLE AND SUBTITLE

Analysis of Depletion-Region Collection in GalnNAs Solar Cells 5a. CONTRACT NUMBER

DE-AC36-99-GO10337

5b. GRANT NUMBER

5c. PROGRAM ELEMENT NUMBER

6. AUTHOR(S)

D.J. Friedman, A.J. Ptak, Sarah R. Kurtz, and J.F. Geisz

NREL/CP-520-37418

5e. TASK NUMBER

PVA54401

5f. WORK UNIT NUMBER

7. PERFORMING ORGANIZATION NAME(S) AND ADDRESS(ES)

National Renewable Energy Laboratory

1617 Cole Blvd.

Golden, CO 80401-3393

9. SPONSORING/MONITORING AGENCY NAME(S) AND ADDRESS(ES)

10. SPONSOR/MONITOR'S ACRONYM(S) NREL

11. SPONSORING/MONITORING AGENCY REPORT NUMBER

12. DISTRIBUTION AVAILABILITY STATEMENT

National Technical Information Service

U.S. Department of Commerce

5285 Port Royal Road

Springfield, VA 22161

13. SUPPLEMENTARY NOTES

14. ABSTRACT (Maximum 200 Words)

We provide qualitative insight into depletion-region collection in GalnNAs cells to (1) understand the effect of diffusion length $L$ on the $Q E$; and (2) describe the magnitude of $L$ required to get adequate current from the cell. We use Wolf's equations for the QE including a drift field $E$, and model $E$ as being equal to the junction built-in voltage distributed uniformly across the depletion region. This allows us to calculate the $Q E$ as a function of $L$ and depletion width $W_{D}$. We show that if $L$ is sufficiently small, increasing $W_{D}$ can actually decrease the $Q E$. To determine how long $L$ needs to be in a practical GalnNAs junction, we calculate from the QE the short-circuit current density as a function of $W_{D}$ and $L$. This allows us to estimate that $L_{\text {ambipolar }}$ needs to be greater than roughly $1 \mu \mathrm{m}$ in order to obtain enough photocurrent for the 4-junction application, giving guidance to the experimental effort to develop such cells.

15. SUBJECT TERMS

PV; depletion-region collection; solar cells; quantum efficiency; drift field; photocurrent;

\begin{tabular}{|c|c|c|}
\hline $\begin{array}{l}\text { a. REPORT } \\
\text { Unclassified }\end{array}$ & $\begin{array}{l}\text { b. ABSTRACT } \\
\text { Unclassified }\end{array}$ & $\begin{array}{l}\text { c. THIS PAGE } \\
\text { Unclassified }\end{array}$ \\
\hline
\end{tabular}

17. LIMITATION
OF ABSTRACT
UL $\quad \begin{array}{ll}\text { 18. } & \begin{array}{l}\text { NUMBER } \\ \text { OF PAGES }\end{array} \\ \end{array}$

19a. NAME OF RESPONSIBLE PERSON

19b. TELEPHONE NUMBER (Include area code) 